\title{
Spectroscopic Properties of Polycyclic Aromatic Compounds. Part IV: Effect of Solvent Polarity and Nitromethane on the Fluorescence Emission Behavior of Select Bipolycyclic Aromatic Hydrocarbons
}

\author{
SHERYL A. TUCKER, JASON M. GRIFFIN, WILLIAM E. ACREE, JR.,* \\ MAXIMILIAN ZANDER, and REGINALD H. MITCHELL \\ Department of Chemistry, University of North Texas, Denton, Texas 76203-5068, U.S.A. (S.A.T., J.M.G., W.E.A.); Rütgerswerke \\ AG, Postfach 2002 41/51/61, D-44558 Castrop-Rauxel, Germany (M.Z.); and Department of Chemistry, University of Victoria, \\ P.O. Box 3055, Victoria, BC V8W 3P6, Canada (R.H.M.)
}

\begin{abstract}
Fluorescence emission behavior is reported for $1,1^{\prime}$-binaphthalene, $2,2^{\prime}$ binaphthalene, 9,9'-bianthracene, 9,9'-biphenanthrene, 1,1'-methylenebisnaphthalene, and 1,1',2,2'-tetrahydro-5,5'-biacenaphthylene dissolved in organic nonelectrolyte solvents of varying polarity, refractive index, and dielectric constant. Fluorescence measurements are used to classify the six bipolycyclic aromatic hydrocarbon (bi-PAH) solutes as either solvatochromic probe or nonprobe molecules, depending upon whether measured fluorescence properties vary with solvent nature. Of the bi-PAHs studied, only 9,9'-bianthracene exhibited probe character. Possible correlations between $9,9^{\prime}$-bianthracene's maximum intensity emission wavelength and select functions of solvent refractive index and dielectric constant were examined. Also reported is the effect that nitromethane has on bi-PAH fluorescence emission intensities.
\end{abstract}

Index Headings: Fluorescence; Molecular structure; Spectroscopic techniques.

\section{INTRODUCTION}

Identification and quantification of polycyclic aromatic hydrocarbons (PAHs) in unknown mixtures require accurate fluorescence emission intensity measurements, as well as the availability of a large spectral data file for comparing the unknown's spectrum against PAH standards. The majority of mixtures commonly encountered contains several isomeric pairs or structurally similar aromatic compounds, which emit in approximately the same spectral regions. Kalman filtering and Gaussian or other curve-fitting techniques, ${ }^{1-6}$ alone or in combination with phase-resolved $d^{7-9}$ or synchronous scanning ${ }^{10-18}$ fluorescence spectroscopy, theoretically allow uncoupling of overlapped spectra. Such methods become less reliable, however, as the number of mixture components increases. High-performance liquid chromatographic (HPLC) separation prior to fluorimetric analysis affords a viable alternative, but again the method is extremely time-consuming whenever large numbers of isomeric compounds are present.

Blümer and Zander ${ }^{19}$ recommended that nitromethane and/or nitrobenzene could be added to a water/acetonitrile ( $20: 80$ by volume) binary mobile phase to selectively suppress fluorescence signals of alternant PAHs. Emission intensities of nonalternant PAHs would remain unchanged. Solutes are classified as alternant PAHs if every

\footnotetext{
Received 31 August 1993; accepted 4 December 1993.

* Author to whom correspondence should be sent.
}

alternant carbon atom in the aromatic ring system can be "starred". Nonalternant PAHs, on the other hand, would have at least one pair of adjacent starred atoms. ${ }^{20,21}$ Published studies ${ }^{22-29}$ involving over 80 PAHs have identified dibenzo[hi,wx] heptacene, benzo[k]fluoranthene, and naphtho[ $2,3 \mathrm{~b}]$ fluoranthene as among the few exceptions to the so-called nitromethane selective quenching rule in the PAH6 benzenoid, fluorenoid, fluoranthenoid, and "methylene-bridged" cyclopenta-PAH subclasses. More recent measurements ${ }^{30}$ revealed that nitromethane quenched fluorescence emission of all nine acenaphthylene derivatives studied thus far, which is completely contrary to what would be expected on the basis of the fact that the nine solutes are nonalternant PAHs.

Although a large spectral data file now exists for several subclasses of polycyclic aromatic compounds, we have not reported the fluorescence emission and quenching behavior of the subclass that contains the bipolycyclic aromatic hydrocarbon (bi-PAH) derivatives. As a continuation of our fluorescence studies ${ }^{22-26,30-38}$ we have measured the fluorescence behavior of $1,1^{\prime}$-binaphthalene, 2,2'-binaphthalene, 9,9'-bianthracene, 9,9'-biphenanthrene, 1, $1^{\prime}$-methylenebisnaphthalene, and $1,1^{\prime}, 2,2^{\prime}$ tetrahydro-5,5'-biacenaphthylene dissolved in neat acetonitrile, toluene/acetonitrile (40:60 percent by volume), and ethyl acetate/acetonitrile (40:60 percent by volume) solvents at different nitromethane concentrations. Molecular structures of these six alternant bi-PAH derivatives are given in Fig. 1. All solutes were also screened for possible solvatochromic and/or solvent polarity probe character. Fluorescence behavior of 9, $9^{\prime}$-bianthracene has been extensively investigated before, ${ }^{39-45}$ in part because the molecule exhibits dual fluorescence resulting from "twisted intramolecular charge transfer" (TICT) excited states, and strong spectral overlap of the TICT band and the anthracene-like "locally excited" (LE) fluorescence band. In nonpolar solvents such as cyclohexane, 9,9' bianthracene has strong emission signals near 395 and $414 \mathrm{~nm}$, which is indicative of the locally excited state. Significant red shifts are observed in the $S_{1} \rightarrow S_{0}$ fluorescence in the more polar solvents like acetonitrile, and they are attributed to formation of an excited-state dipole with a full electronic charge separation. Because of the perpendicular ground-state geometry, ${ }^{46-48}$ the two anthracene moieties in $9,9^{\prime}$-bianthracene are orbitally decoupled ${ }^{49}$ and fulfill the "minimum overlap rule", 


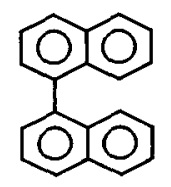

A

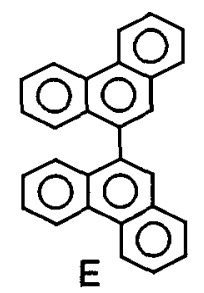

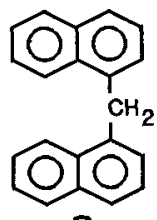

B

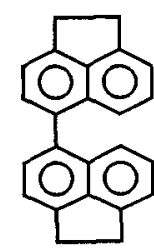

C

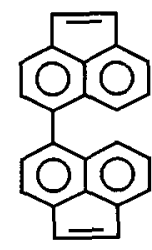

D

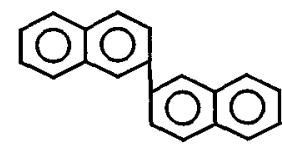

$F$

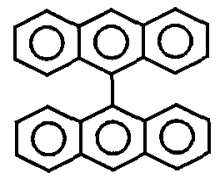

G
FIG. 1. Molecular structures of the bipolycyclic aromatic hydrocarbon solutes: (A) 1,1'-binaphthalene; (B) 1,1'-methylenebisnaphthalene; (C) 1,1',2,2'-tetrahydro-5, $5^{\prime}$-biacenaphthylene; (D) 5,5'-biacenaphthylene; (E) 9,9'-biphenanthrene; (B) 2,2'-binaphthalene; and (G) 9,9'-bianthracene.

a precondition for full electron transfer. Fluorescence properties of other bi- and tri-PAHs have been examined to a much lesser extent. ${ }^{53-56}$ To our knowledge, no one has ever reported the effect that nitromethane has on biPAH fluorescence emission.

\section{MATERIALS AND METHODS}

Bi-PAH solutes $\mathbf{A}, \mathbf{B}, \mathbf{E}, \mathbf{F}$, and $\mathbf{G}$ were highly purified samples from the collection of reference substances of the spectroscopy laboratory of Rütgerswerke AG, CastropRauxel, Germany. 1,1'2,2'-tetrahydro-5,5'biacenaphthylene and 5,5'-biacenaphthylene were synthesized and purified by procedures described in the chemical literature. ${ }^{57}$ Stock solutions were prepared by dissolving the solutes in dichloromethane. Small aliquots of the stock solutions were transferred into test tubes, allowed to evaporate, and diluted with the solvent of interest. Final solute concentrations of $10^{-5} \mathrm{M}$ (or less) were sufficiently dilute to minimize both primary and secondary inner-filtering artifacts. Solvents were of HPLC, spectroquality or AR grade, purchased commercially from either Aldrich or Fisher Scientific, and the resulting solutions were optically dilute (absorbances $<0.01 \mathrm{~cm}^{-1}$ ) at all wavelengths, except for the nitromethane quenching studies.

Absorption spectra were recorded on a Milton Roy Spectronic 1001 Plus and a Hewlett-Packard 8450A photodiode array spectrophotometer in the usual manner. The fluorescence spectra were run on a Shimadzu RF$5000 \mathrm{U}$ spectrofluorometer with the detector set at high sensitivity. Solutions were excited at $300 \mathrm{~nm}\left(1,1^{\prime}\right.$-binaphthalene), $304 \mathrm{~nm}$ (2,2'-binaphthalene), $360 \mathrm{~nm}\left(9,9^{\prime}\right.$ bianthracene), $300 \mathrm{~nm}\left(9,9^{\prime}\right.$-biphenanthrene), $290 \mathrm{~nm}$ $\left(1,1^{\prime}\right.$-methylenebisnaphthalene), and $300 \mathrm{~nm}\left(1,1^{\prime}, 2,2^{\prime}-\right.$ tetrahydro-5,5'-biacenaphthylene). Fluorescence data were accumulated in a $1-\mathrm{cm}^{2}$ quartz cuvette at $19^{\circ} \mathrm{C}$, ambient room temperature, with excitation and emission slit width settings of 15 and $3 \mathrm{~nm}$, respectively. The bi-PAH fluorescence spectra, depicted in Figs. 2 and 3, represent a single scan which was then solvent blank corrected and verified by repetitive measurements. A seventh solute, 5,5'-biacenaphthylene, could not be studied because the

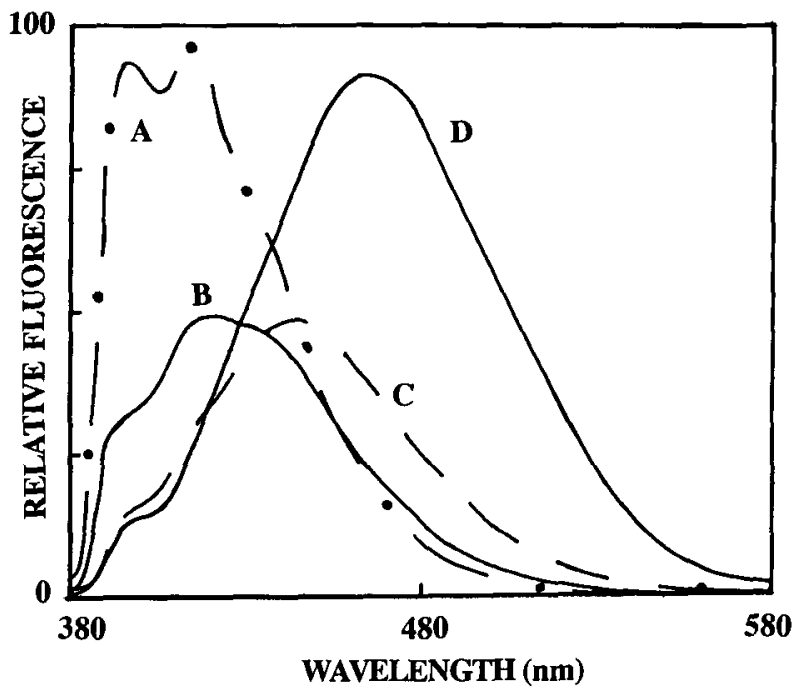

FIG. 2. Fluorescence emission spectra of 9,9'-bianthracene dissolved in $[A(-.-)] n$-hexadecane; $[B(-)]$ butyl acetate; $[C(---)]$ dichloromethane; and $[D(-)]$ dimethyl sulfoxide.

observed emission of a $\sim 10^{-5} \mathrm{M}$ solution was much too weak to permit accurate intensity determination after solvent blank correction. Absorption measurements indicated that the low emission signals were caused, in part, by secondary inner filtering resulting from solute selfabsorption of emission radiation. Fluorescence measurements at slightly higher and lower 5,5'-biacenaphthylene concentrations proved unsuccessful.

Emission intensities associated with the quenching study were corrected for primary inner-filtering artifacts arising from the absorption of excitation radiation. Several of the bi-PAHs have excitation wavelengths in the 280-320 $\mathrm{nm}$ spectral region, and a few drops of nitromethane gave solutions having appreciable absorbances. Mathematical expressions, computational procedures, and interrogation zone dimensions are given elsewhere..$^{23,25,58,59}$ Every effort was made to work at solution absorbances $\leq 0.95 \mathrm{~cm}^{-1}$ $\left(f_{\text {prim }} \leq 3.0\right)$, where the inner-filtering correction equation

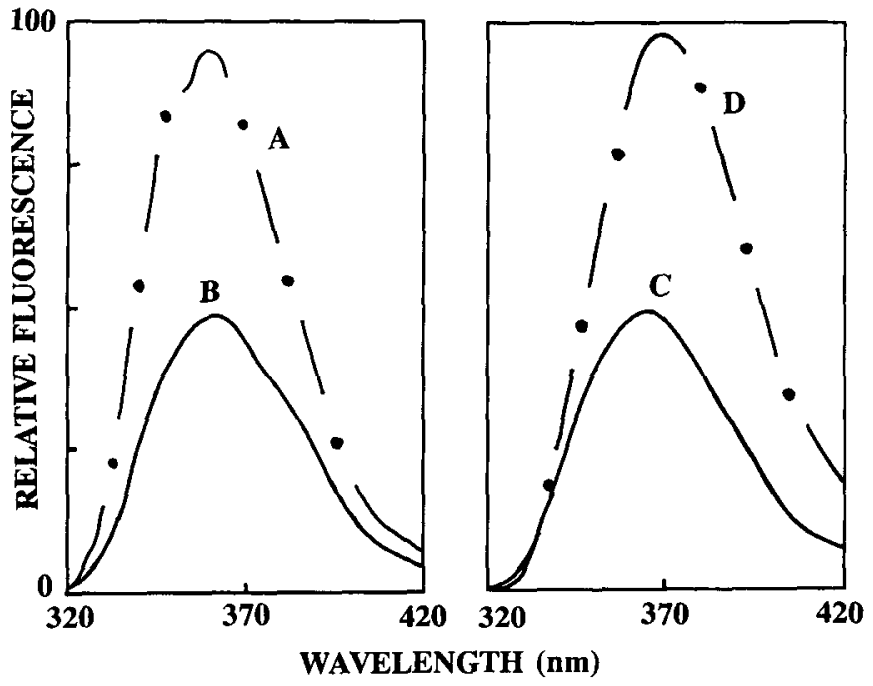

Fig. 3. Fluorescence emission spectra of 1,1'-binaphthalene dissolved in $[A(-\cdot-)] n$-hexadecane; $[B(-)]$ butyl acetate; $[C(-)]$ dichloromethane; and $[D(-\cdot-)]$ dimethyl sulfoxide. 
TABLE I. Refractive index, dielectric constant, and major excitation and emission wavelengths of 9,9'-bianthracene for various organic solvents.

\begin{tabular}{|c|c|c|c|c|}
\hline Organic solvent & $n^{\mathrm{a}}$ & $\epsilon^{\mathrm{h}}$ & $\begin{array}{c}\lambda_{\mathrm{ex}} \\
(\mathrm{nm})\end{array}$ & $\begin{array}{c}\lambda_{\mathrm{cm}} \\
(\mathrm{nm})^{\mathrm{c}}\end{array}$ \\
\hline$n$-Hexane & 1.3749 & 1.890 & 366 & 394,411 \\
\hline$n$-Heptane & 1.3876 & 1.92 & 365 & 394,411 \\
\hline Cyclohexane & 1.4262 & 2.023 & 366 & 394,413 \\
\hline Methylcyclohexane & 1.4231 & 2.02 & 366 & 395,413 \\
\hline 2,2,4-Trimethylpentane & 1.3915 & 1.94 & 365 & 392,411 \\
\hline$n$-Hexadecane & 1.4345 & 2.04 & 366 & 396,414 \\
\hline Dibutyl amine & 1.4177 & 2.978 & 368 & $s-395,416$ \\
\hline Carbon tetrachloride & 1.4602 & 2.238 & 370 & $s-395,416$ \\
\hline Dibutyl ether & 1.3992 & 2.8 & 366 & s-394, 414 \\
\hline 1-Octanol & 1.4295 & 10.34 & 367 & s-392, 418 \\
\hline p-Xylene & 1.4958 & 2.270 & 368 & $\mathrm{~s}-395,418$ \\
\hline o-Xylene & 1.5055 & 2.568 & 369 & $\mathrm{~s}-395,418$ \\
\hline $\mathrm{MTBE}^{\mathrm{d}}$ & & & 366 & $\mathrm{~s}-392,414$ \\
\hline$m$-Xylene & 1.4972 & 2.374 & 368 & $\mathrm{~s}-395,418$ \\
\hline 1-Pentanol & 1.41 & 14.27 & 366 & s-396, 435 \\
\hline Ethyl ether & 1.3524 & 4.335 & 366 & 392,414 \\
\hline Toluene & 1.4968 & 2.568 & 369 & $\mathrm{~s}-396,414$ \\
\hline Benzene & 1.5011 & 2.284 & 370 & $\mathrm{~s}-395,419$ \\
\hline 1-Butanol & 1.3993 & 17.8 & 366 & s-392, 437 \\
\hline $1-\mathrm{C}$ & 1.4021 & 7.39 & 366 & $\mathrm{~s}-392,416$ \\
\hline Chlorobenzer & 1.5241 & 5.708 & 370 & $s-395,430$ \\
\hline 1-Prop & 1.3856 & 20.33 & 366 & s-395, 437 \\
\hline Cyclohexanol & 1.4641 & 15.77 & 367 & s-400, 434 \\
\hline 2-Propanol & 1.3772 & 18. & 366 & s-390, 435 \\
\hline Ethanol & 1.3614 & 25.41 & 366 & $\mathrm{~s}-392,442$ \\
\hline form & 1.4459 & 4.806 & 370 & s-397, 434 \\
\hline Butyl & 1.3942 & 5.01 & 366 & s-395, 419 \\
\hline Methanol & 1.3284 & 33.62 & 366 & s-395, 448 \\
\hline Tetra & 1.4071 & 7.61 & 367 & $s-392,434$ \\
\hline hane & 1.4242 & 9.08 & 368 & $\mathrm{~s}-394,442$ \\
\hline Eth & 1.3723 & 6.095 & 366 & $\mathrm{~s}-395,432$ \\
\hline $1,2-\mathrm{D}$ & 1.4448 & 10.4 & 369 & $s-395,443$ \\
\hline Dimethyl carbonate & 1.3682 & 3.084 & 366 & $s-392,435$ \\
\hline 4-Methyl-2-pentanone & 1.3957 & 13.11 & 367 & s- 394,438 \\
\hline 1,4-Dioxane & 1.4224 & 2.2 & 368 & s-398, 419 \\
\hline Dimethyl adipate & & & 368 & s-395, 437 \\
\hline 2-Butanone & 1.3788 & 18.51 & 366 & 392,443 \\
\hline Dibutyl oxala & & & 368 & s- 395,434 \\
\hline glycol & 8 & 38.66 & 369 & s-392, 464 \\
\hline Aceto & 1.3587 & 21.19 & 366 & s-392, 446 \\
\hline Acetonitrile & 1.3441 & 37.5 & 366 & $s-392,461$ \\
\hline$N, N$-Dimethy & 1.4380 & 37.8 & 368 & s- 395,454 \\
\hline$N, N$-Dimethylforn & 1.4305 & 36.7 & 368 & $s-395,458$ \\
\hline Propy & 1.4210 & 64.80 & 368 & s-394, 464 \\
\hline Dimethyl sulfoxide & 1.4783 & 46.7 & 371 & s-397, 464 \\
\hline
\end{tabular}

${ }^{a}$ Experimental values taken from the literature at $20^{\circ} \mathrm{C} .62-65$

b Experimental values taken from the literature at $20^{\circ} \mathrm{C} .{ }^{64-73}$

c The "s-" denotes a shoulder.

"Methyl tert-butyl ether.

is valid. Secondary inner-filtering corrections were not necessary in the present since nitromethane is "optically transparent" in most of these bi-PAHs' emission ranges.

\section{RESULTS AND DISCUSSION}

Representative fluorescence emission spectra of $9,9^{\prime}-$ bianthracene and 1,1'-binaphthalene dissolved in $n$-hexadecane, butyl acetate, dichloromethane, and dimethyl sulfoxide are depicted in Figs. 2 and 3. These four nonelectrolyte solvents were judiciously selected to encompass the entire Py range of solvent polarity, from the nonpolar $n$-hexadecane to the moderately polar butyl acetate and dichloromethane to the very polar dimethyl sulfoxide, which is one of the most polar solvents on the Py scale. The Py solvent polarity scale is based upon the fluorescence properties of pyrene (a known PAH solvent polarity probe molecule) and is defined as the ratio of emission intensities of the first and third vibronic bands, i.e., Py $=I_{1} / I_{3}$. Inspection of Figs. 2 and 3 reveals that the fluorescence emission spectra of bi-PAHs, unlike those of their PAH counterparts, show little detailed emission fine structure. For many of the 45 nonelectrolyte solvents considered, 1,1'-binaphthalene, 2,2'-binaphthalene, 9,9'bianthracene, 9,9'-biphenanthrene, 1,1'-methylenebisnaphthalene, and $1,1^{\prime}, 2,2^{\prime}$-tetrahydro-5, $5^{\prime}$-biacenaphthylene exhibited only a single, fairly broad emission band. Two simpler PAH molecules, anthracene and phenanthrene, have four and five emission bands in their fluorescence spectrum in the $320-480 \mathrm{~nm}$ spectral region. ${ }^{60,61}$

Figure 2 documents that 9,9-bianthracene does show solvatochromic behavior, as evidenced by rather pronounced changes in the location of its emission band. In nonpolar solvents, such as cyclohexane, two bands of comparable intensity were observed at $\sim 395$ and 414 $\mathrm{nm}$. Significant red shifts were noted in the $S_{1} \rightarrow S_{0}$ fluorescence in the more polar dimethyl sulfoxide solvent. Excitation wavelength remained essentially constant and unaffected by solvent polarity (see Table I). As stated in the Introduction, these particular observations have been reported in several previous publications; ${ }^{39-45}$ however, the 45 solvents in Table I comprise one of the more comprehensive steady-state fluorescence studies completed to date. Our fluorescence wavelengths of $\sim \lambda_{\mathrm{cm}}=$ $413 \mathrm{~nm}$ and $\lambda_{\mathrm{em}}=416 \mathrm{~nm}$ for methylcyclohexane and 1 -chlorobutane, and Stoke's shifts of $\Delta \nu=\left(1 / \lambda_{\mathrm{ex}}\right)-(1 /$ $\left.\lambda_{\mathrm{em}}\right)=4.9 \times 10^{3} \mathrm{~cm}^{-1}$ and $\Delta y=5.4 \times 10^{3} \mathrm{~cm}^{-1}$ for acetone and acetonitrile, respectively, are in good agreement with values of $\lambda_{\mathrm{em}}=422 \mathrm{~nm}, \lambda_{\mathrm{em}}=425 \mathrm{~nm}, \Delta \nu=$ $3.50 \times 10^{3} \mathrm{~cm}^{-1}$, and $\Delta \nu=4.30 \times 10^{3} \mathrm{~cm}^{-1}$ cited in a recent paper by Kabouchi et al..$^{43}$ Slight variations in wavelength and frequency shifts are to be expected when one is comparing fluorescence data recorded on different instruments, due to differences in wavelength calibration, wavelength-dependent photomultiplier detector response, optical component efficiencies, excitation/emission slit widths and/or solvent blank correlations. (Note: Kabouchi et al. ${ }^{43}$ gave very little information in terms of their experimental procedure.) Also, 9,9'-bianthracene's broad emission band and shoulders make exact determination of $\lambda_{\mathrm{em}}$ subject to greater experimental uncertainty; this factor contributes in part to the differences noted between our Stokes shifts and those reported in the chemical literature. For any given spectrofluorometer, measured $\Delta \nu$ values for a series of solvents should be internally consistent.

Of the remaining five bi-PAH solutes studied, 1, 1'binaphthalene showed the second-most solvatochromic behavior. The observed $10-\mathrm{nm}$ shift in emission wavelength, however, was much too small to allow us to ever recommend 1,1'-binaphthalene as a useful solvent polarity probe molecule in fluid solution. Pankasem and Thomas $^{53}$ have successfully used $1,1^{\prime}$-binaphthalene as a room-temperature luminescent probe for monitoring active sites on $\gamma$-alumina. When adsorbed onto a solid surface, free rotation of the two naphthyl moieties about the $\mathrm{C}-\mathrm{C}$ single bond connecting both aromatic ring systems is hindered. 1,1'-Binaphthalene thus exists in two distinct planar conformations, each of which exhibits different 


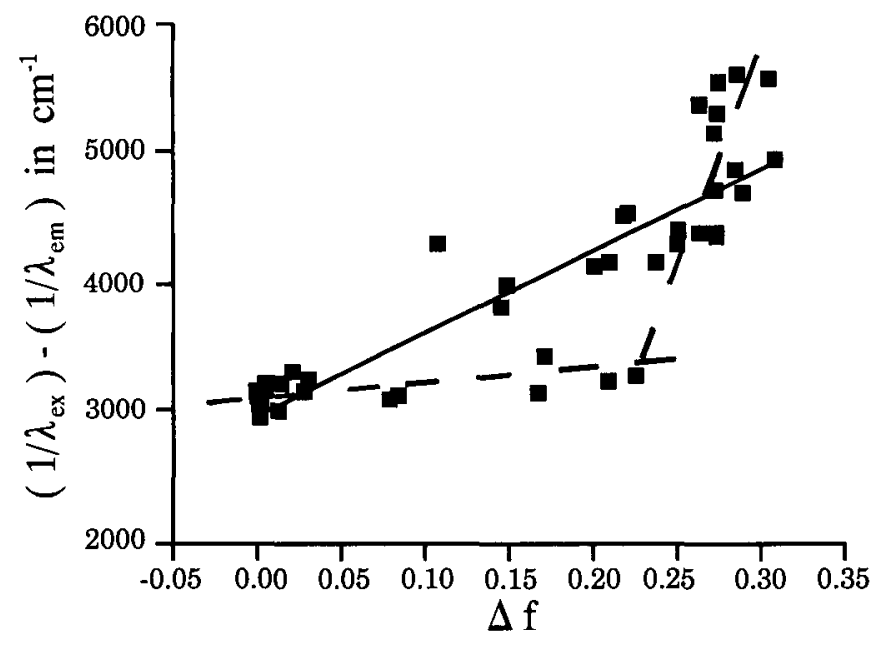

FIG. 4. Graphical plot of Stokes shift vs. Lippert $\Delta f$ function (see Eq 1) for 9,9'-bianthracene dissolved in $\mathbf{4 2}$ nonelectrolyte solvents listed in Table I. The solid straight line was determined via linear least-squares regressional analysis using all 42 data points for which $n$ and $\epsilon$ values exist. Dashed lines represent a plausible separation of solvents according to fluorophore excited state, either the anthracene-like LE (nearly horizontal) or the TICT excited state (nearly vertical).

photophysical behavior. In solution, rotation is significantly faster. The observed emission spectra in Fig. 3 likely correspond to some "equilibrium average" of the two planar conformers plus all intermediate rotational conformers, rather than that of a single conformer. The solvatochromic shift will be less pronounced in fluid solution.

To a first approximation, specific effects are ignored. The energy difference (in $\mathrm{cm}^{-1}$ ) between the solvated ground- and excited-state fluorophore can be described by either the Lippert equation: ${ }^{74-77}$

$$
\begin{aligned}
\left(1 / \lambda_{\mathrm{ex}}\right)-\left(1 / \lambda_{\mathrm{em}}\right) \approx & (2 / h c)[(\epsilon-1) /(2 \epsilon+1) \\
& \left.-\left(n^{2}-1\right) /\left(2 n^{2}+1\right)\right] \\
& \times\left[\left(\mu^{*}-\mu\right)^{2} / a^{3}\right]+\text { constant } \\
\approx & k[(\epsilon-1) /(2 \epsilon+1) \\
& \left.\quad-\left(n^{2}-1\right) /\left(2 n^{2}+1\right)\right] \\
& + \text { constant }
\end{aligned}
$$

or modified forms of the Lippert equation:43,78,79

$$
\begin{aligned}
\left(1 / \lambda_{\mathrm{ex}}\right)-\left(1 / \lambda_{\mathrm{em}}\right) \approx & k[(\epsilon-1) /(2 \epsilon+1) \\
& \left.-\beta\left(n^{2}-1\right) /\left(2 n^{2}+1\right)\right] \\
& + \text { constant }
\end{aligned}
$$

or the Bilot-Kawski Eq. 3 (with $\beta$ equal to unity): ${ }^{80}$

$$
\begin{aligned}
& \left(1 / \lambda_{\mathrm{ex}}\right)-\left(1 / \lambda_{\mathrm{em}}\right) \\
& \approx k\left[(\epsilon-1) /(2 \epsilon+1)-\left(n^{2}-1\right) /\left(2 n^{2}+2\right)\right] \\
& \div\left\{\left[1-\beta\left(n^{2}-1\right) /\left(2 n^{2}+2\right)\right]^{2}\right. \\
& \quad \times[1-\beta(\epsilon-1) /(2 \epsilon+2)]\}+ \text { constant }
\end{aligned}
$$

where $\epsilon$ and $n$ refer to the dielectric constant and refractive index of the solvent, respectively; $c$ is the speed of light; $h$ denotes Planck's constant; and $a$ is the radius of the solvent cavity wherein the fluorophore resides. The latter

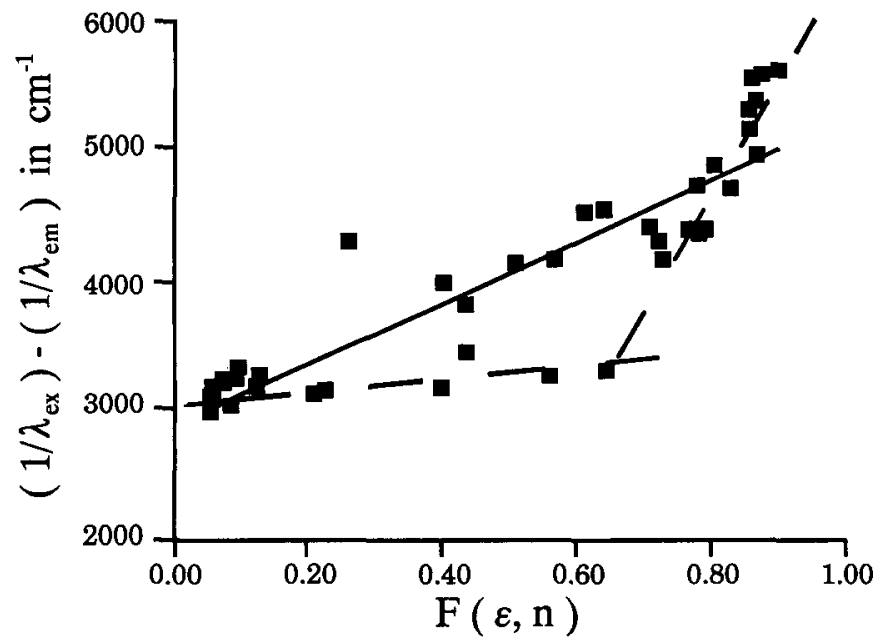

FIG. 5. Graphical plot of Stokes shift vs. Bilot-Kawski $F(\epsilon, n)$ parameter (see Eq. 3) for 9,9'-bianthracene dissolved in 42 nonelectrolyte solvents listed in Table I. The solid straight line was determined via linear least-squares regressional analysis using all 42 data points for which $n$ and $\epsilon$ values exist. Dashed lines represent a plausible separation of solvents according to fluorophore excited state, either the anthracenelike LE (nearly horizontal) or the TICT excited state (nearly vertical).

three quantities, along with the dipole moments of the fluorophore's excited $\left(\mu^{*}\right)$ and ground state $(\mu)$, are assumed to be solvent independent (i.e., there is no major change in electronic transition type and no major change in the geometrical reorganization within the excited state) and are thus combined into the proportionality constant, $k$. Figures 4 and 5 graphically depict Stokes shifts (in $\mathrm{cm}^{-1}$ ) for $9,9^{\prime}$-bianthracene vs. Lippert $\Delta f$ function (see Eq. 1) and Stokes shift vs. Bilot-Kawski $F(\epsilon, n)$ function (Eq. 3), respectively. Forty-two of the 45 nonelectrolyte solvents studied are included in the plots and subsequent statistical analysis. Methyl tert-butyl ether, dimethyl adipate, and dibutyl oxalate had to be excluded because refractive indices and static dielectric constants for these three solvents could not be found in the chemical literature. Linear least-squares regressional analysis showed that the observed values,

$$
\begin{gathered}
\left(1 / \lambda_{\mathrm{ex}}\right)-\left(1 / \lambda_{\mathrm{em}}\right)=\Delta \nu=2993.4+6322.7 \Delta f \\
\left(r^{2}=0.73\right) \\
\left(1 / \lambda_{\mathrm{ex}}\right)-\left(1 / \lambda_{\mathrm{em}}\right)=\Delta \nu=2873.6+2381.2 F(\epsilon, n) \\
\left(r^{2}=0.79\right),
\end{gathered}
$$

are only marginally correlated at best. There is considerable scatter in the data points around each of the socalled "best straight lines", which were determined via least-squares analysis.

One can argue that such nonlinear behavior is typical of fluorophores having two (or more) excited states (i.e., an anthracene-like locally excited state and a twisted intramolecular charge transfer excited state), in that each state would have a different dipole moment. The multiplicative $\left[\left(\mu^{*}-\mu\right)^{2} / a^{3}\right]$ factor in Eq. 1 would be constant for only a single excited state, not for both the LE and TICT excited states of 9,9'-bianthracene. It should be theoretically possible though, to separate the solvents into two groups on the basis of whether the LE or the TICT excited state is observed. The dashed lines in Figs. 4 and 


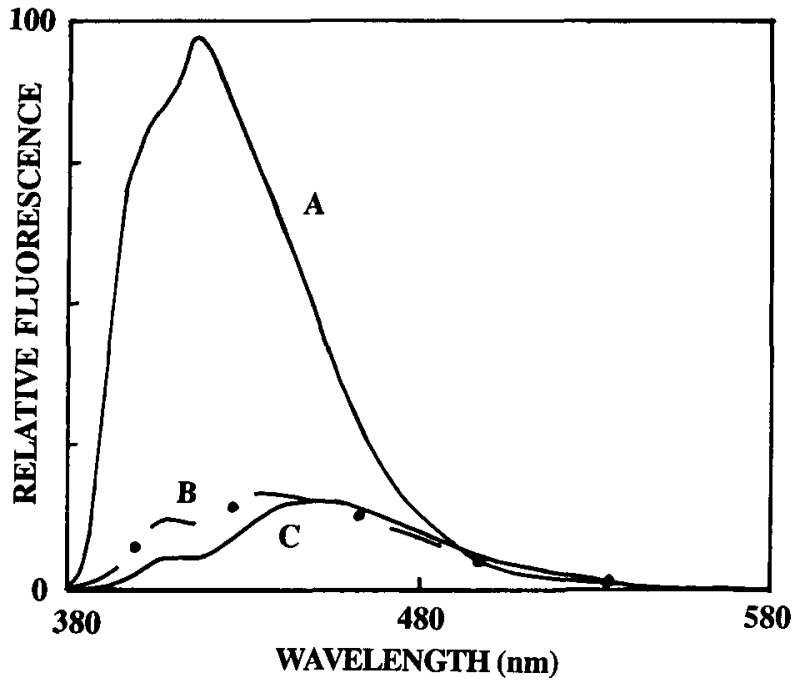

FIG. 6. Fluorescence emission spectra for 9,9'-bianthracene dissolved in carbon tetrachloride as a function of irradiation time. From top to bottom, spectra correspond to 0,65 , and $120 \mathrm{~min}$. The emission spectrum obtained at $180 \mathrm{~min}$ of irradiation overlayed perfectly with the bottom 120-min irradiation spectrum. Results shown are for irradiation at $360 \mathrm{~nm}$. Similar spectra were obtained 9,9'-bianthracene-carbon tetrachloride solutions irradiated at $300 \mathrm{~nm}$.

5 show one plausible separation scheme. Least-squares analysis gives for each of the separate lines the following mathematical equations:

$$
\begin{gathered}
\left(1 / \lambda_{\mathrm{ex}}\right)-\left(1 / \lambda_{\mathrm{em}}\right)=\Delta \nu=3136.5+722.5 \Delta f \\
(\text { LE excited state }) \\
\left(1 / \lambda_{\mathrm{ex}}\right)-\left(1 / \lambda_{\mathrm{em}}\right)=\Delta \nu=-857.0+20,773.1 \Delta f
\end{gathered}
$$

(TICT excited state)

for regressional analysis according to the Lippert equation. Data points for 1,2-dichloroethane, dichloromethane, chlorobenzene, chloroform, cyclohexanol, tetrahydrofuran, dimethyl carbonate, and ethyl acetate do not visually appear to belong to either dashed line, and these eight solvents were excluded from the statistical treatment. Kabouchi et al. ${ }^{43}$ presented a similar two-line graph; however, the authors listed only five solvents (also see Ref. 81).

Interestingly, half of the eight solvents that were excluded from the dashed-line least-squares treatment contained at least one chlorine atom. In earlier papers ${ }^{82-84}$ we rationalized abnormal fluorescence behavior of PAH and PANH solute probes in select chloroalkane solvents in terms of photochemical reactions. Carbon tetrachloride, and to a much lesser extent chloroform and dichloromethane, is known to undergo irreversible photochemical reactions with several PAH solutes. ${ }^{85-92}$ The photochemical reaction of carbon tetrachloride with anthracene is believed to involve the formation of two free radical species, as suggested by the following reaction mechanism: ${ }^{85}$

$$
\begin{aligned}
\mathrm{PAH}+h \nu & \rightarrow{ }^{1} \mathrm{PAH}^{*} \\
{ }^{1} \mathrm{PAH}^{*}+\mathrm{CCl}_{4} & \rightleftharpoons{ }^{1}\left(\mathrm{PAH}-\mathrm{CCl}_{4}\right)^{*} \\
{ }^{\mathrm{I}}\left(\mathrm{PAH}-\mathrm{CCl}_{4}\right)^{*} & \rightarrow{ }^{3}\left(\mathrm{PAH}-\mathrm{CCl}_{4}\right)^{*} \rightarrow{ }^{3} \mathrm{PAH}^{*}+\mathrm{CCl}_{4} \\
{ }^{1}\left(\mathrm{PAH}-\mathrm{CCl}_{4}\right)^{*} & \rightarrow \cdot \mathrm{PAH}-\mathrm{Cl}+{ }^{\cdot} \mathrm{CCl}_{3} \rightarrow \text { Products }
\end{aligned}
$$

where superscripts 1 and 3 denoted excited singlet and triplet states, respectively. The isolated major product was identified as 9-chloro-10-trichloromethyl-9,10-dihydroanthracene. Reaction mechanisms for the larger PAH molecules are expected to be more complex and to include several major products. In fact, Wiczk and Latowski ${ }^{92}$ noted that reaction products resulting from irradiation of pyrene and perylene in carbon tetrachloride had molecular formulas of $\mathrm{C}_{16} \mathrm{H}_{9} \mathrm{Cl}, \mathrm{C}_{17} \mathrm{H}_{9} \mathrm{Cl}_{3}, \mathrm{C}_{33} \mathrm{H}_{19} \mathrm{Cl}_{3}, \mathrm{C}_{17} \mathrm{H}_{10} \mathrm{Cl}_{4}$, $\mathrm{C}_{18} \mathrm{H}_{8} \mathrm{Cl}_{6}, \mathrm{C}_{33} \mathrm{H}_{16} \mathrm{Cl}_{4}$, and $\mathrm{C}_{34} \mathrm{H}_{20} \mathrm{Cl}_{6}$ and of $\mathrm{C}_{20} \mathrm{H}_{11} \mathrm{Cl}$, $\mathrm{C}_{20} \mathrm{H}_{10} \mathrm{Cl}_{2}, \mathrm{C}_{20} \mathrm{H}_{9} \mathrm{Cl}_{3}, \mathrm{C}_{22} \mathrm{H}_{10} \mathrm{Cl}_{4}$, and $\mathrm{C}_{22} \mathrm{H}_{12} \mathrm{Cl}_{4}$, respectively. The authors, however, did not attempt to identify the various products formed.

In an experiment to determine whether an undesired photochemical reaction was responsible for several chlorinated solvents being off the dashed lines, solutions of 9,9'-bianthracene dissolved in carbon tetrachloride and chloroform were irradiated at 300 and $360 \mathrm{~nm}\left(\lambda_{\mathrm{ex}}\right.$ for the bi-PAH solute) for a prolonged period of time. Fluorescence emission spectra were recorded periodically, and any differences from the original spectrum (at time zero) were noted. As shown in Fig. 6, there is a rather dramatic reduction in the measured emission signal for 9, $9^{\prime}$-bianthracene dissolved in carbon tetrachloride with increasing irradiation time. After 65 min of irradiation at $360 \mathrm{~nm}$ (and $300 \mathrm{~nm}$, not shown) the emission signal was approximately one-sixth of its original value, and the maximum intensity emission wavelength had red-shifted from 418 to $435 \mathrm{~nm}$, with a fairly broad shoulder beginning to appear at $454 \mathrm{~nm}$. Fifty-five minutes of additional irradiation decreased the 418 -nm emission intensity by another $50 \%$, while the $454-n m$ peak grew slightly. The emission spectrum remained constant for the third hour of irradiation. In the case of chloroform solvent, there were no visual changes noted in 9,9'-bianthracene's emission spectrum, even after $2 \mathrm{~h}$ of continued irradiation at both 300 and $360 \mathrm{~nm}$. For these measurements, the presence of oxygen (air) was not excluded. However, since no spectral changes were observed when chloroform was used as the solvent, the observed changes in carbon tetrachloride cannot be due to photooxidation. On the basis of the fact that it took us about $5 \mathrm{~min}$ (or less) to record 9,9'bianthracene's emission spectrum, we conclude that, while photochemical reactions may occur, they are much too slow to be responsible for the chlorinated solvents deviating from the Lippert (see Fig. 4) and Bilot-Kawski (see Fig. 5) relationships.

Previous studies ${ }^{19,22-30}$ involving nitromethane as a selective quenching agent for discriminating between alternant vs. nonalternant PAHs utilized either neat acetonitrile or a binary aqueous/acetonitrile mixture (20:80 percent by volume) in order to have sufficient polarity! dielectric constant to facilitate electron transfer. Such solvents work well as mobile phases in HPLC separation for those PAHs that contain six rings or less, but different solvent strengths must be employed for larger PAHs having six to ten rings. Toluene/acetonitrile or ethyl acetate/ acetonitrile mixtures have served well as HPLC mobilephase solvents for the separation of the larger PAHs. ${ }^{93,94}$ One or two pasteur pipette drops of nitromethane (per 3 $\mathrm{mL}$ of solution) was found to effectively quench fluorescence emission of 1,1'-binaphthalene, 2,2'-binaphthalene, 9,9'-biphenanthrene, 1,1'-methylenebisnaphtha- 
lene, and $1,1^{\prime}, 2,2^{\prime}$-tetrahydro-5, 5'-biacenaphthylene dissolved in neat acetonitrile and in binary toluene/acetonitrile (40:60 percent by volume) and ethyl acetate/ acetonitrile (40:60 percent by volume) solvent mixtures. After correction for primary inner filtering, the calculated emission intensity was reduced to roughly $10-25 \%$ of its original value. Emission quenching was less pronounced in the case of 9,9'-bianthracene since five pasteur pipette drops of nitromethane only halved the original emission signal, again after correction for primary inner-filtering effects.

\section{ACKNOWLEDGMENTS}

This work was supported in part by grants from the National Science Foundation (Grant No. CTS-8922485), by the University of North Texas Research Council, and by a National Science Foundation Doctoral Research Fellowship awarded to S. A. Tucker. J. M. Griffin also thanks the UNT Texas Academy of Math and Science (TAMS) for an undergraduate summer research scholarship.

1. R. E. Kalman, J. Basic Eng. 82, 34 (1964)

2. S. C. Rutan, J. Chemom. 1, 7 (1987).

3. S. D. Brown, Anal. Chim. Acta 181, 1 (1986).

4. S. C. Rutan, D. D. Gerow, and G. Hartmann, Intell. Lab. Sys. 3, 61 (1988)

5. H. Gampp, M. Maeder, C. J. Meyer, and A. D. Zuberbühler, Talanta 32, 1133 (1985).

6. M. Maeder, Anal. Chem. 59, 527 (1987).

7. D. W. Millican and L. B. McGown, Appl. Spectrosc. 46, 28 (1992).

8. D. W. Millican and L. B. McGown, Anal. Chem. 61, 580 (1989).

9. D. W. Millican and L. B. McGown, Anal. Chem. 62, 2242 (1990).

10. T. Vo-Dinh, in Modern Fluorescence Spectroscopy, E. L. Wehry, Ed. (Plenum Press, New York, 1981), Vol. 4, pp. 167-192.

11. T. Vo-Dinh and P. R. Martinex, Anal. Chim. Acta 125, 13 (1981).

12. T. Vo-Dinh, R. B. Gammage, A. R. Hawthorne, and J. H. Thorngate, Environ. Sci. Technol. 12, 1297 (1978).

13. J. J. Santana Rodriguez, Z. Sosa Ferrera, A. Afonso Perara, and V. Gonzalez Diaz, Talanta 39, 1611 (1992).

14. A. B. Marin-Lazaro, J. Hernandez Garcia, and J. J. Santana Rodriguez, Fresenius J. Anal. Chem. 343, 509 (1992).

15. J. J. Santana Rodriguez, Z. Sosa Ferrera, A. Afonso Perera, and V. Gonzalez Diaz, Anal. Chim. Acta 255, 107 (1991).

16. M. J. Kerkhoff, T. M. Lee, E. R. Allen, D. A. Lundgren, and J. D. Winefordner, Environ. Sci. Technol. 19,695 (1985).

17. L. A. Files, B. T. Jones, S. Hanamura, and J. D. Winefordner, Anal. Chem. 58, 1440 (1986).

18. P. Baudot, M. L. Viriot, J. C. Andre, J. Y. Jezequel, and M. Lafontaine, Analusis 19, 85 (1991).

19. G.-P. Blümer and M. Zander, Fresenius Z. Anal. Chem. 296, 409 (1979).

20. H. E. Zimmerman, Quantum Mechanics for Organic Chemists (Academic Press, New York, 1975), pp. 145-146.

21. J. March, Advanced Organic Chemistry: Reactions, Mechanisms and Structure (McGraw-Hill, New York, 1968), pp. 46-48.

22. S. A. Tucker, W. E. Acree, Jr., B. P. Cho, R. G. Harvey, and J. C. Fetzer, Appl. Spectrosc. 45, 1699 (1991).

23. V. L. Amszi, Y. Cordero, B. Smith, S. A. Tucker, W. E. Acree, Jr., C. Yang, E. Abu-Shaqara, and R. G. Harvey, Appl. Spectrosc. 46, 1156 (1992).

24. S. A. Tucker, H. Darmodjo, W. E. Acree, Jr., J. C. Fetzer, and M. Zander, Appl. Spectrosc. 46, 1260 (1992).

25. S. A. Tucker, W. E. Acree, Jr., J. C. Fetzer, and J. Jacob, Polycyclic Aromat. Compds. 3, 1 (1992).

26. S. A. Tucker and W. E. Acree, Jr., Appl. Spectrosc. 46, 1388 (1992).

27. H. Dreeskamp, E. Koch, and M. Zander, Z. Naturforsch. 30A, 1311 (1975).

28. U. Breymann, H. Dreeskamp, E. Koch, and M. Zander, Chem. Phys. Lett. 59, 68 (1978).

29. S. H. Chen, C. E. Evans, and V. L. McGuffin, Anal. Chim. Acta 246, 65 (1991).

30. S. A. Tucker, H. C. Bates, V. L. Amszi, W. E. Acree, Jr., H. Lee,
P. Di Raddo, R. G. Harvey, J. C. Fetzer,and G. Dyker, Anal. Chim. Acta 278, 269 (1993).

31. R. Waris, M. A. Rembert, D. M. Sellers, W. E. Acree, Jr., K. W Street, Jr., C. F. Poole, P. H. Shetty, and J. C. Fetzer, Appl. Spectrosc. 42, 1525 (1988).

32. R. Waris, M. A. Rembert, D. M. Sellers, W. E. Acree, Jr., K. W. Street, Jr., and J. C. Fetzer, Analyst 114, 195 (1989).

33. R. Waris, W. E. Acree, Jr., K. W. Street, Jr., and J. C. Fetzer, Appl Spectrosc. 43, 845 (1989).

34. W. E. Acree, Jr., S. A. Tucker, A. I. Zvaigzne, K. W. Street, Jr. J. C. Fetzer, and H.-F. Grutzmacher, Appl. Spectrosc. 44, 477 (1990)

35. W. E. Acree, Jr., S. A. Tucker, L. E. Cretella, A. I. Zvaigzne, K. W Street, Jr., J. C. Fetzer, K. Nakasuji, and I. Murata, Appl. Spectrosc. 44, 951 (1990)

36. S. A. Tucker, A. I. Zvaigzne, W. E. Acree, Jr., J. C. Fetzer, and M. Zander, Appl. Spectrosc. 45, 424 (1991).

37. S. A. Tucker, I.-L. Teng, W. E. Acree, Jr., and J. C. Fetzer, Appl Spectrosc. 45, 186 (1991).

38. W. E. Acree, Jr., S. A. Tucker, and J. C. Fetzer, Polycyclic Aromat. Compds. 2, 75 (1991).

39. F. Schneider and E. Lippert, Ber. Bunsen-Ges. Phys. Chem. 72, 1155 (1968)

40. R. J. Visser, P. C. M. Weisenborn, P. J. M. van Kan, B. H. Huizer, C. A. G. O. Varma, J. M. Warman, and M. P. DeHaas, J. Chem. Soc., Faraday Trans. 2 81, 689 (1985).

41. H. Lueck, M. W. Windsor, and W. Rettig, J. Phys. Chem. 94, 4550 (1990).

42. W. Jarzeba, M. Kahlow, and P. F. Barbara, J. Imaging Sci. 33, 53 (1989).

43. B. Kabouchi, B. Benali, M. Fadouach, A. Kadiri, C. Cazeau-Dubroca, and G. Nouchi, Spectrochim. Acta 48A, 1015 (1992).

44. S. M. Bystryak, G. I. Likhtenshten, and A. I. Kotel'niko, Khim. Fiz. 11, 374 (1992).

45. R. Wortmann, S. Lebus, K. Elich, S. Assar, N. Detzer, and W. Liptay, Chem. Phys. Lett. 198, 220 (1992).

46. W. Rettig and M. Zander, Ber. Bunsen-Ges. Phys. Chem. 87, 1143 (1983).

47. K. Yamasaki, K. Arita, O. Kajimoto, and K. Hara, Chem. Phys. Lett. 123, 277 (1986).

48. L. R. Khundkar and A. H. Zewail, J. Chem. Phys. 84, 1302 (1986).

49. W. Rettig, in Modern Models of Bonding and Delocalization, $\mathrm{J}$ Liebman and A. Greenberg, Eds. (VCH Publishers, New York, 1988), Chap. 5.

50. Z. R. Grabowski, R. Rotkiewicz, A. Siemiarczuk, D. J. Cowley, and W. Baumann, Nouv. J. Chim. 3, 443 (1979)

51. W. Rettig, Angew. Chem., Int. Ed. Engl. 25, 971 (1986) and references therein.

52. Z. R. Grabowski and J. Dobkowski, Pure Appl. Chem. 55, 245 (1983).

53. S. Pankasem and J. K. Thomas, J. Phys. Chem. 95, 7385 (1991).

54. S.-K. Gundermann, E. Romahn, and M. Zander, Z. Naturforsch 47A, 877 (1992)

55. F. Hirayama, J. Chem. Phys. 42, 3163 (1965).

56. F. A. Chandross and C. J. Dempster, J. Am. Chem. Soc. 92, 3586 (1970).

57. R. H. Mitchell, M. Chaudhary, R. V. Williams, R. Fyles, J. Gibson, M. J. Ashwood-Smith, and A. J. Fry, Can. J. Chem. 70, 1015 (1992).

58. S. A. Tucker, W. E. Acree, Jr., M. J. Tanga, S. Tokita, K. Hiruta, and H. Langhals, Appl. Spectrosc. 46, 229 (1992).

59. S. A. Tucker, V. L. Amszi, and W. E. Acree, Jr., J. Chem. Educ. 69, A8 (1992).

60. S. M. Meyerhoffer and L. B. McGown, Anal. Chem. 63, 2082 (1991).

61. N. de Kruijf and R. Verspoor, Fluorescence Spectra of 25 Polycyclic Aromatic Compounds (TNO CIVO-Institutes, Zeist, 1983).

62. TRC Thermodynamic Tables: Hydrocarbons, K. N. Marsh, Ed. (Texas A\&M University, College Station).

63. TRC Thermodynamic Tables: Non-Hydrocarbons, K. N. Marsh, Ed. (Texas A\&M University, College Station).

64. D. R. Linde, Handbook of Chemistry and Physics (CRC Press, Boca Raton, Florida, 1990), 71 st ed.

65. J. A. Dean, Lange's Handbook of Chemistry (McGraw-Hill, New York, 1985), 13th ed.

66. G. E. Papanastasiou and I. I. Ziogas, J. Chem. Eng. Data 36, 46 (1991)

67. E. Musset, A. Nikuradse, and R. Ulbrich, Z. Angew. Phys. 8, 8 (1956).

68. G. Ritzoulis, Can. J. Chem. 67, 1105 (1989). 
69. R. H. Cole, J. Chem. Phys. 9, 251 (1941).

70. E. L. Grove and G. E. Walden, J. Chem. Eng. Data 10, 98 (1965).

71. R. Schmid, J. Solution Chem. 12, 135 (1983).

72. J.-M. Thiebaut, J.-L. Rivail, and J.-L. Greffe, J. Chem. Soc., Faraday Trans. II 72, 2024 (1976).

73. J. A. Riddick and W. B. Bunger, Organic Solvents: Physical Properties and Methods of Purification (John Wiley and Sons, New York, 1970), 3rd ed.

74. J. R. Lakowicz, Principles of Fluorescence Spectroscopy (Plenum Press, New York, 1983), pp. 190-205.

75. E. Von Lippert, Z. Electrochem. 61, 962 (1957).

76. A. Kawski, Acta Phys. Pol. 29, 507 (1966).

77. N. Mataga, Y. Kaifu, and M. Koizumi, Bull. Chem. Soc. Japan 29, 465 (1956).

78. K. Kalyanasundaram and J. K. Thomas, J. Am. Chem. Soc. 99, 2039 (1977).

79. A. Nakajima, Bull. Chem. Soc. Japan 44, 3272 (1971).

80. S. Mazumdar, R. Manoharan, and S. Dogra, J. Photochem. Photobiol. 46A, 301 (1989).

81. F. Schneider, Thesis, Berlin (1969).
82. S. A. Tucker, L. E. Cretella, R. Waris, K. W. Street, Jr., W. E. Acree, Jr., and J. C. Fetzer, Appl. Spectrosc. 44, 269 (1990).

83. S. A. Tucker, W. E. Acree, Jr., and M. J. Tanga, Appl. Spectrosc. 45, 57 (1991).

84. S. A. Tucker, W. E. Acree, Jr., M. J. Tanga, M. Zander, J. C. Fetzer, S. Tokita, K. Hiruta, K. Kitahara, and H. Nishi, Appl. Spectrosc. 45, 1188 (1991)

85. N. Selvarajan, M. M. Panicker, S. Vaidyanathan and V. Ramakrishnan, Indian J. Chem. 18A, 23 (1979)

86. M. V. Encinas, M. A. Rubio and E. A. Lissi, J. Photochem. 18, 137 (1982).

87. W. M. Wiczk and T. Latowski, Z. Naturforsch. 42A, 1290 (1987).

88. E. J. Bowen and K. K. Rohatgi, Disc. Faraday Soc. 14, 146 (1953).

89. M. I. Ivanoff, Bull, Soc. Chim. Belg. 71, 759 (1962).

90. G. K. Oster, Acta Phys. Polon. 26, 435 (1964).

91. F. A. Carroll and D. A. Whitten, J. Phys. Chem. 80, 2046 (1976).

92. W. M. Wiczk and T. Latowski, Polish J. Chem. 64, 373 (1990).

93. J. C. Fetzer and W. R. Biggs, Chromatographia 27, 118 (1989).

94. P. A. Peaden, M. L. Lee, Y. Hirata, and M. V. Novotny, Anal. Chem. 52, 2268 (1980) 